\title{
STUDIES ON GANGRENE FOLLOWING COLD INJURY. II. GEN- ERAL COURSE OF EVENTS IN RABBIT FEET AND EARS FOLLOWING UNTREATED COLD INJURY ${ }^{1}$
}

\author{
By FREDERICK A. FUHRMAN AND J. M. CRISMON \\ (From the Department of Physiology, Stanford University School of Medicine, \\ Stanford University, California)
}

(Received for publication September 1, 1946)

In part I of this series (1) a method for the production of controlled cold injury (frostbite) of the ears and feet of rabbits was described, and data were given illustrating the incidence of gangrene and extent of tissue loss following injury. The general course of events, including gross changes, skin color, and temperature measurements of injured ears and feet will be given here.

\section{EXPERIMENTAL RESULTS}

\section{A. Gross changes following injury}

Following immersion of the ear of rabbits for periods ranging from 60 seconds to 10 minutes, at temperatures from $-32^{\circ} \mathrm{C}$. to $-70^{\circ} \mathrm{C}$., the entire frostbitten portion of the ear becomes gangrenous and is eventually lost (1). Loss of the entire injured part of hind feet occurs after exposure for 3 minutes at temperatures of $-45^{\circ} \mathrm{C}$. or lower and after 60 minute exposure at $-15^{\circ}$ C. The gross changes following injury of various degrees in which actual freezing of the tissues occurs are at first similar enough so that a general description will suffice.

Immediately upon removal from the freezing mixture the ear or foot is solidly frozen, stiff and pale greyish-pink in color (Figure 1-A). The ear and toes are not "brittle" in that they cannot be broken when bent between the fingers. This observation is in agreement with the work of Ariev (2) who found that brittleness of frozen fingers, ears, and whole frogs and mice did not occur until a tissue temperature of about $-80^{\circ} \mathrm{C}$. was reached.

In ears, thawing is first evident in the region immediately surrounding the central artery and in

1 The work described in this paper was done under a contract recommended by the Committee on Medical Research, between the Office of Scientific Research and Development and Stanford University. the proximal frostbitten region immediately distal to the unfrozen part of the ear. After about 3 minutes, blood flow in the larger vessels becomes apparent. Within 5 minutes, the frozen region is thawed. The vessels are engorged with blood and the temperature of the frostbitten portion of the ear rises rapidly. Swelling of the ear is first evident in the region immediately surrounding the larger vessels, especially around the central artery. The edema first involves only the frostbitten region and then extends proximally until the entire ear is swollen to approximately 4 times the initial volume (3). During the first several hours after injury the advancing edge of the edematous area is clearly visible and may be seen to progress proximally toward the base of the ear. This edge is frequently pointed in the center, with the point lying in the region of the central artery. Blisters form on the inner surface of the frostbitten portion of the ear about 1 to 6 hours after frostbite. They are most commonly seen overlying the central artery, about $1 \mathrm{~cm}$. from the tip. Profuse exudation of fluid from the injured portion of the ear is seen 1 to 2 days after frostbite. A crust of dried protein usually forms.

Three to 4 days after injury the frostbitten portion of the ear becomes cool and the cartilage of this region appears to be entirely lacking in elasticity. This change marks the beginning of the period of "wet gangrene" during which no blood flow is demonstrable. Drying becomes grossly evident by the fourth to the sixth day. Fluid loss from the gangrenous tissue occurs largely by surface evaporation, although in the earlier stages some may be taken up via the lymphatics and intact circulation of the neighboring normal tissue. The dried mummified part may remain attached for several weeks but is eventually lost. Loss of tissue has in all cases involved only the frostbitten area and does not extend into the proximal, un- 
injured portion of the ear. The edge of the surviving stump is at first somewhat red and thickened by induration. The redness and induration disappear within a few weeks and are replaced by firm scar tissue well covered by hair-free epithelium at the edge where separation occurred.

In feet, thawing begins at the proximal part of the frostbitten region. It occurs first superficially, and the skin may become pliable while the deeper tissues are still hard. Once the foot is thawed it warms rapidly to temperatures about $5^{\circ} \mathrm{C}$. below body temperature. Swelling begins when blood flow is reestablished. It occurs first only in the injured region, and then extends up the leg (Fig. 1-B). The color of the foot becomes darker within 2 hours; at this and somewhat later times the dorsal surface of the foot may be engorged with blood, extremely cyanotic, and moist. Exudation occurs through any skin abrasions. Swelling reaches a maximum in the frostbitten region within 6 hours after injury, although further fluid loss to the foot may occur after this time (3). Since the skin over the frostbitten part of the foot is maximally distended, the fluid is forced into the leg and may reach the thigh. After 1 to 4 hours, blisters appear on the hair-free toe pads and are always confined to that region. The edema begins to diminish after 1 to 3 days, depending upon the severity of the injury. Exudation and wet gangrene follow severe injuries (1). Fluid is lost both externally and internally as in the ears. The foot shrinks and areas of wet gangrene become dry within 2 to 3 days (Figure 1-C). The dried, mummified part remains attached for several weeks (Figure 1-D). In a few cases (about 2 per cent, all involving colored rabbits) the animals chewed the dead portions and rapidly removed the stump. More often it was worn away by the movement of the animals in the cage or separated spontaneously after about 3 weeks.

\section{B. Skin color changes following injury}

In spite of the ultimate development of gangrene in frostbitten ears and feet of rabbits there is abundant evidence that, for some period between the moment of injury by cold and the appearance of unmistakable signs of ischemia and death of tissue, blood flows through the injured region, often at faster rates than are encountered in uninjured tissues.

In the period immediately after the frozen part is removed from the freezing mixture and before the completion of thawing, the skin color changes from a faintly pink, opaque grey to bright pink. The bright pink color appears first over the large blood vessels and is most strikingly apparent in the ear. The color change in the ear is noticeable within the first 3 minutes after removal from the freezing mixture. Within 5 minutes, the pink color deepens to a bright red and spreads in all directions from the larger vessels. Edema formation begins early in this period of hyperemia, but, in spite of the accumulating fluid, the injured part does not begin to take on a cyanotic appearance until the edema is well advanced. In sharp contrast to the persistent bright red color of the injured regions when they are allowed to thaw at room temperature is the immediate deep cyanosis that is produced by rapid thawing of the tissues in water at $41^{\circ}$ to $42^{\circ} \mathrm{C}$. (a method of treatment to be described later). In the rapidly thawed ears and feet, good arterial pulses can be felt, but cyanosis is present and marked from the time of return of blood flow.

Examination of the central artery of the ear in the region proximal to the injured portion shows that the period of marked dilatation lasts for about 1 hour after frostbite. Between the first and second hour after frostbite, there is a progressive constriction of the central artery in the normal part of the ear while the portion of the artery within the injured area retains its wide diameter. Close observation with the aid of transillumination shows that the apparent gross diameter of this vessel does not correspond with the width of the column of blood contained but is, in part, due to perivascular edema.

In general, skin color of the normal part of the ear parallels accurately the changes in blood flow which are indicated by the skin temperature measurements described below. Between 4 and 24 hours after frostbite, the massive edema and hyperemia tend to obscure the early sharp differentiation between the appearance of the frostbitten and the normal part, but demarcation of the two regions again becomes clear with the development of deepening cyanosis of the injured area. The 
association of the cyanosis with reduced flow of blood is indicated by the accompanying fall in skin temperature of the distal portion of the ear as compared with the uninjured portion and by the weakening and final disappearance of palpable pulsations in the distal segment of the central artery.

While the details of the circulation cannot be so clearly made out in the frostbitten feet of rabbits, the changes in skin color are very similar to those observed in the ears.

\section{Skin temperature changes following cold injury \\ 1. Methods for measurement of skin temperature}

Measurements of skin temperature of rabbit feet and ears following frostbite were made continuously during the first day following injury and at intervals during the next 120 hours. Readings were taken routinely for 5 minutes with each of 5 iron-constantan thermocouples which were soldered to thin copper discs $7 \mathrm{~mm}$. in diameter and secured to the skin by means of "Sealskin" (polyvinyl butyral in isopropyl alcohol and castor oil). Temperatures were recorded on a Leeds and Northrup Micromax recording potentiometer.

On frostbitten feet the thermocouples were placed between the third and fourth toes and on the dorsal and plantar surfaces of the foot in the midline, about $1.5 \mathrm{~cm}$. proximal to the base of the toes. On the normal foot the thermocouples were placed in the same relative positions, although in many cases only the toe and dorsum temperatures of the normal foot were measured.

On frostbitten ears one thermocouple was placed about $1 \mathrm{~cm}$. from the margin and far enough laterally from the midline to avoid the central artery, another about 2 to 3 $\mathrm{cm}$. proximal to this in the injured region, and a third about $3 \mathrm{~cm}$. proximal to the line to which the ear was immersed.

Although the measurements of skin temperature were not made in a constant temperature room, the air temperature of the laboratory was relatively constant $\left(25^{\circ}\right.$ C.) and varied only about $\pm 1^{\circ} \mathrm{C}$. from day to day and throughout a single day. Care was taken to shield the thermocouples from ambient air currents by use of a tubular gauze sock slipped over the ear or foot after the thermocouples were in place. Some experiments were carried out with the foot or ear encased in a cellophane jacket. It was found that the skin temperature changes were very similar whether or not the cellophane jackets were used, except that gangrenous toes and tips of ears tended to be warmed by the warm air inside the cellophane. The experiments reported are those in which cellophane was not used.

\section{Time course of temperature changes following injury}

Following 60- or 90-second exposure of an ear at $-55^{\circ} \mathrm{C}$., the temperature of the frostbitten portion increases rapidly until the maximum is reached in 20 to 60 minutes. This temperature is usually $32^{\circ} \mathrm{C}$. to $35.5^{\circ} \mathrm{C}$. The proximal, uninjured part of the frostbitten ear is usually several degrees warmer than that of the contralateral ear. The temperature of the frostbitten part of the ear is maintained within a few degrees of the maximum temperature attained for the first 3 to 5 hours following injury; after this a progressive fall in skin temperature is observed. Figure 2 shows the mean skin temperature of the ears of 3 animals for 120 hours following 90-second immersion at $-55^{\circ} \mathrm{C}$. It is clear from this figure that the mean temperature of the tip of the injured ears is lower than that of the normal ears 5 hours after injury and that it falls continuously during the first 50 hours after injury until it reaches a level $1^{\circ}$ to $2^{\circ} \mathrm{C}$. above room temperature. Wet gangrene appears about 48 hours after injury and drying occurs after 72 hours. Thus the reduction in blood flow to the ear is not immediately brought about by frostbite but is a continuous process occurring during the first 50 hours after exposure. The stabilization of skin temperature of the injured region at a low level marks the beginning of the stage of wet gangrene.

Fig. 1. General Course of Events Following Frostbite of Rabbit Feet Produced by LIQUID IMMERSION

A. Appearance of frozen foot, 20 minutes after removal from freezing mixture at $-52^{\circ} \mathrm{C}$. (3 minute immersion). Thawing has not yet occurred.

B. Edematous foot 3 hours after immersion for 3 minutes at $-45^{\circ} \mathrm{C}$. Foot volume 2.6 times initial volume.

C. Appearance of foot 4 days after injury produced by immersion for 3 minutes at $-55^{\circ} \mathrm{C}$. showing wet gangrene on the dorsal surface.

D. Dry, mummified foot 7 days after frostbite produced by immersion for 3 minutes at $-55^{\circ} \mathrm{C}$. 

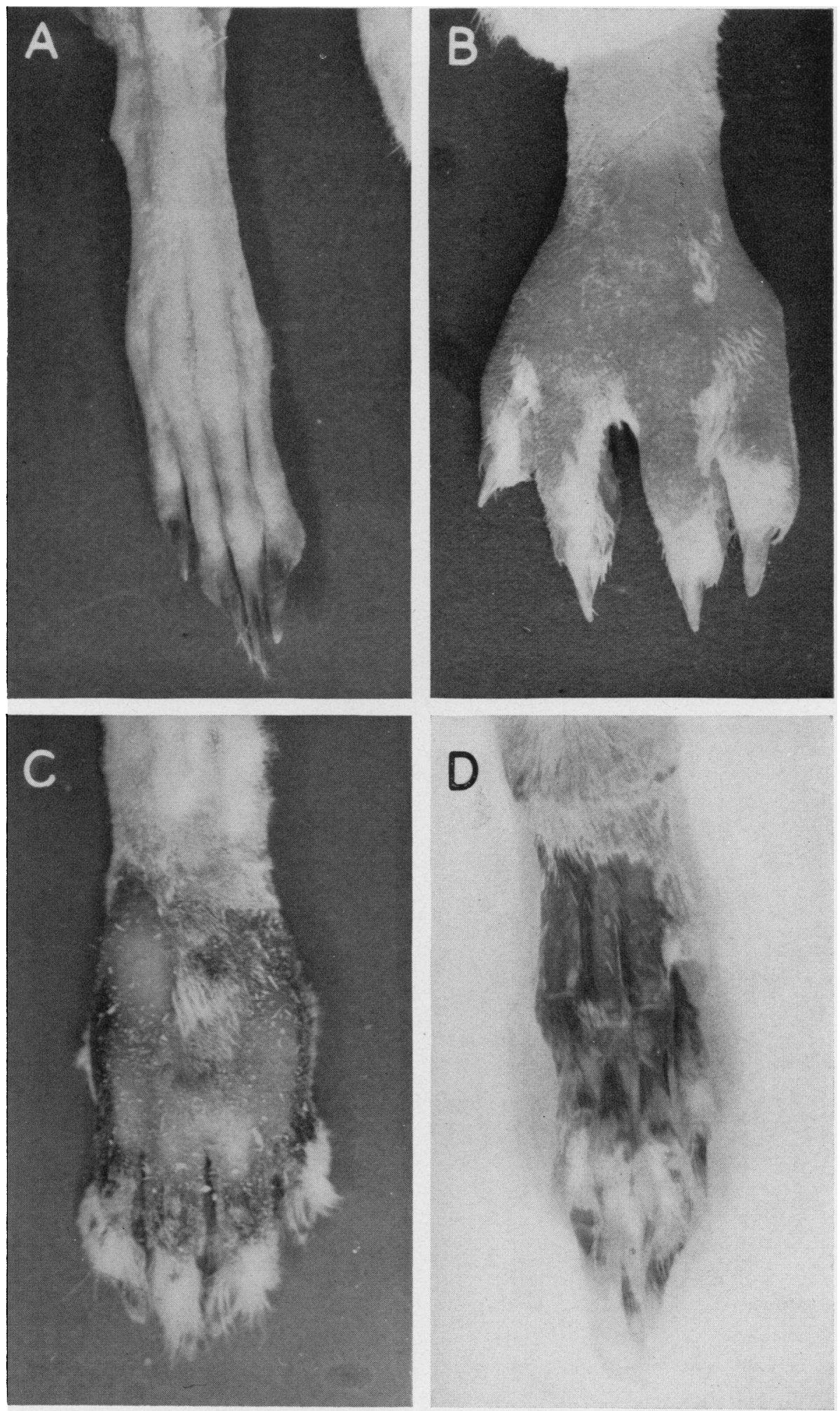

FIG. 1 


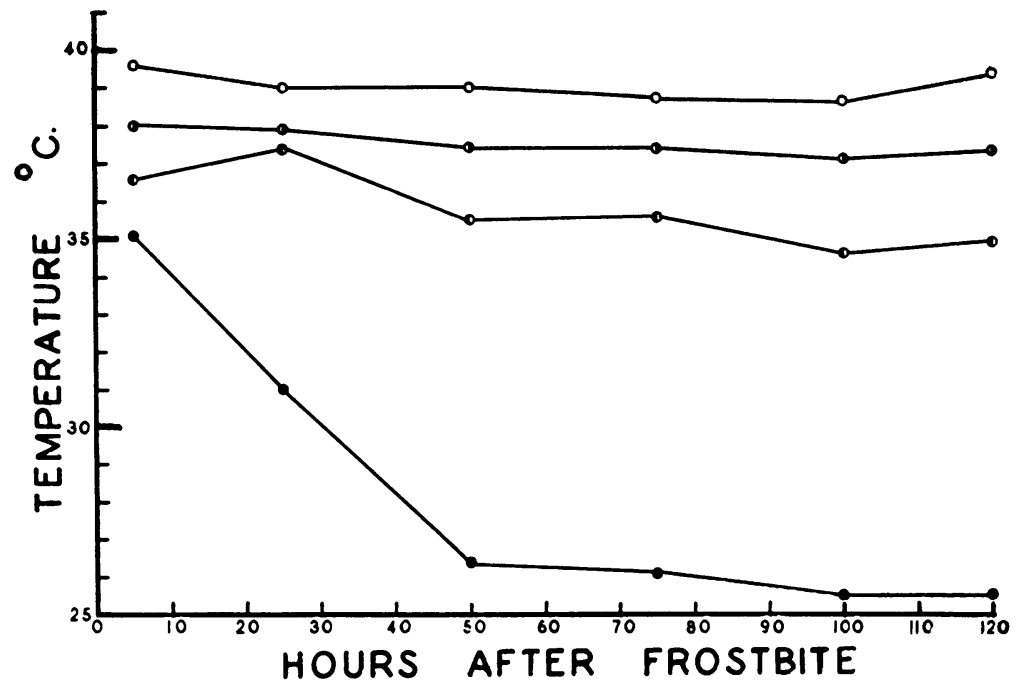

Fil; 2. Tine Course of Skin Temperature Changes in Rabbit Ears after Exposlre of the Distal Part of the Ears at $-55^{\circ}$ C. For 90 Seconds. Rectal Temperatures Are also Show

Mean data from three animals are plotted in the figure.

Open circles....... Rectal temperature

- ....... Unexposed proximal portion of frostbitten ear

- $\quad . . .$. Tip of normal ear

Solid circles....... Tip of frostbitten ear

Rabbits' feet removed from the freezing liquid remain solidly frozen for about 20 minutes after 3-minute immersion at $-55^{\circ} \mathrm{C}$. After thawing. the temperature rises rapidly as blood flow to the injured region is reestablished. Within 1 hour the temperature of the frostbitten toes reaches a maximum of $28^{\circ}$ to $31^{\circ} \mathrm{C}$. This temperature is maintained for a variable period. sometimes not more than 20 to 30 minutes: a progressive fall in temperature of the toes then occurs until it reaches $26^{\circ}$ to $30^{\circ} \mathrm{C}$. after 4 hours. The maximum temperature of the dorsum of the injured foot is attained 20 to 30 minutes earlier than that of the toes and remains $2^{\circ}$ to $3^{\circ}$ above that of the toes. After 4 hours it has fallen to $31^{\circ}$ to $33^{\circ} \mathrm{C}$. Figure 3 shows the mean temperatures of frostbitten feet ( 3 minutes exposure at $-55^{\circ}$ C.) and the contralateral feet of three animals during a period of 120 hours after injury. It may be seen that the dorsum and toes of the frostbitten feet show consistently lower temperatures than does the dorsum of the normal foot for the first 50 hours after injury. After this time the skin temperatures of the dorsal surfaces of the injured and normal feet closely parallel each other. The tempera- ture of the frostbitten toes remains lowest during the entire time and eventually falls even farther when the toes dry and become mummified. The tissue loss in these animals (Figure 3 ) involves the toes and most of the dorsal surface of the feet. The relatively high temperature of the dorsum of the injured feet may be attributed to persistence of blood flow in deeper vessels, arising from the plantar arch. A limited number of measurements of skin temperature of the plantar surface of the foot indicates that it may be several degrees higher than that of the dorsal surface.

When the foot is exposed at $-55^{\circ} \mathrm{C}$. for only 1 minute, which usually produces only severe edema but no loss of tissue, the initial temperatures which are attained by the toes of the frostbitten foot are higher than after 3 minutes of exposure. Within 1 hour after injury the toes usually reach a temperature of about $35^{\circ} \mathrm{C}$. $\left(33^{\circ}\right.$ to $38^{\circ} \mathrm{C}$.), and then fall several degrees during the first 4 hours. The temperature of the dorsum of the frostbitten foot is often $1^{\circ}$ to $2^{\circ} \mathrm{C}$. higher than that of the contralateral dorsum. In 2 animals, in which the toes were lost following a 1-minute exposure at $-55^{\circ} \mathrm{C}$., the temperature of the toes 
dropped sharply after 40 to 50 hours to a level only $2^{\circ}$ to $3^{\circ} \mathrm{C}$. above room temperature. This drop in temperature of the toes, which are eventually lost, is progressive and coincides in time with the other local signs of gangrene.

\section{Relationship of skin temperature changes to tissue loss}

The temperatures of normal and frostbitten feet have been further analyzed in consideration of the extent of subsequent tissue loss in the injured feet. The temperature of the toes of the frostbitten foot has been compared with the temperature of the dorsal surface of the normal foot of the same animal at various times during the first 6 hours after injury. The data for these comparisons are given in Table I.

The column in Table I headed "Temperature difference" gives for each animal the mean of a number of comparisons between the temperatures of the injured toes and the dorsum of the normal foot during the first 6 hours. The column headed "P" expresses the probability that such differences would occur through errors in random sam-
TABLE I

Comparison of skin temperatures during the first six hours after injury in normal and frostbitten rabbit feet Feet frostbitten by immersion at $-55^{\circ} \mathrm{C}$. for the time indicated

\begin{tabular}{|c|c|c|c|c|c|}
\hline \multirow{2}{*}{$\begin{array}{c}\text { Dura- } \\
\text { tion }\end{array}$} & \multirow[t]{2}{*}{ Tissue loss } & \multicolumn{2}{|c|}{$\begin{array}{l}\text { Skin temperature. } \\
\text { Mean of determi- } \\
\text { nations during } \\
\text { first six hours }\end{array}$} & \multirow{2}{*}{$\begin{array}{c}\begin{array}{c}\text { Tem- } \\
\text { perature } \\
\text { diff. } \\
\text { oC. }\end{array} \\
\text { FB-N }\end{array}$} & \multirow[t]{2}{*}{$P^{1}$} \\
\hline & & $\begin{array}{l}\text { Frost- } \\
\text { bitten }\end{array}$ & Normal & & \\
\hline $\begin{array}{l}1 \\
1 \\
1 \\
1\end{array}$ & $\begin{array}{l}\text { None } \\
\text { None } \\
\text { None } \\
\text { None }\end{array}$ & $\begin{array}{l}36.8^{\circ} \\
34.1^{\circ} \\
38.5^{\circ} \\
37.9^{\circ}\end{array}$ & $\begin{array}{l}32.8^{\circ} \\
36.0^{\circ} \\
38.5^{\circ} \\
35.8^{\circ}\end{array}$ & $\begin{array}{c}+4.0^{\circ} \\
-1.9^{\circ} \\
0 \\
+2.1^{\circ}\end{array}$ & $\begin{array}{l}0.500 \\
0.020 \\
0.200 \\
0.020\end{array}$ \\
\hline $\begin{array}{l}1 \\
1\end{array}$ & $\begin{array}{l}\text { Distal phalanges } \\
\text { All digits }\end{array}$ & $\begin{array}{l}33.6^{\circ} \\
29.8^{\circ}\end{array}$ & $\begin{array}{l}35.6^{\circ} \\
37.0^{\circ}\end{array}$ & $\begin{array}{l}-2.0^{\circ} \\
-7.2^{\circ}\end{array}$ & $\begin{array}{l}0.010 \\
0.001\end{array}$ \\
\hline $\begin{array}{l}3 \\
3 \\
3\end{array}$ & $\begin{array}{l}\text { Entire foot } \\
\text { Entire foot } \\
\text { Entire foot }\end{array}$ & $\begin{array}{l}27.5^{\circ} \\
29.7^{\circ} \\
32.8^{\circ}\end{array}$ & $\begin{array}{l}30.9^{\circ} \\
35.8^{\circ} \\
35.7^{\circ}\end{array}$ & $\begin{array}{l}-3.4^{\circ} \\
-6.1^{\circ} \\
-2.9^{\circ}\end{array}$ & $\begin{array}{l}0.001 \\
0.001 \\
0.001\end{array}$ \\
\hline
\end{tabular}

$1 P$ expresses the probability that such differences would occur through errors in random sampling.

pling. These probabilities were calculated by the " $t$ " test of Fisher (4).

At a time after injury when the gross appearance of the injured feet provides no indication of impending gangrene, differences in skin tempera-

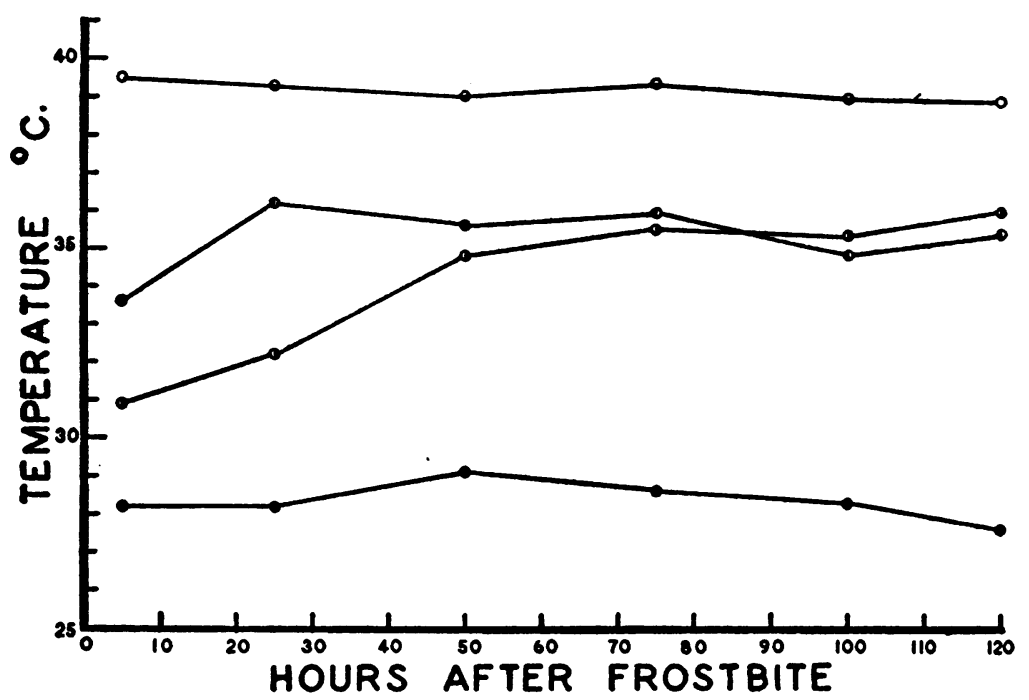

Fig. 3. Time Course of Skin Temperature Changes in Rabbit Feet after Exposure of Feet at $-55^{\circ}$ C. for Three Minutes. Rectal Temperatures Are also Shown

Mean data from four animals are plotted in the figure.

Open circles........ Rectal temperature

- ....... Dorsum of normal foot

- ........ Dorsum of frostbitten foot

Solid circles........Toes of frostbitten foot 


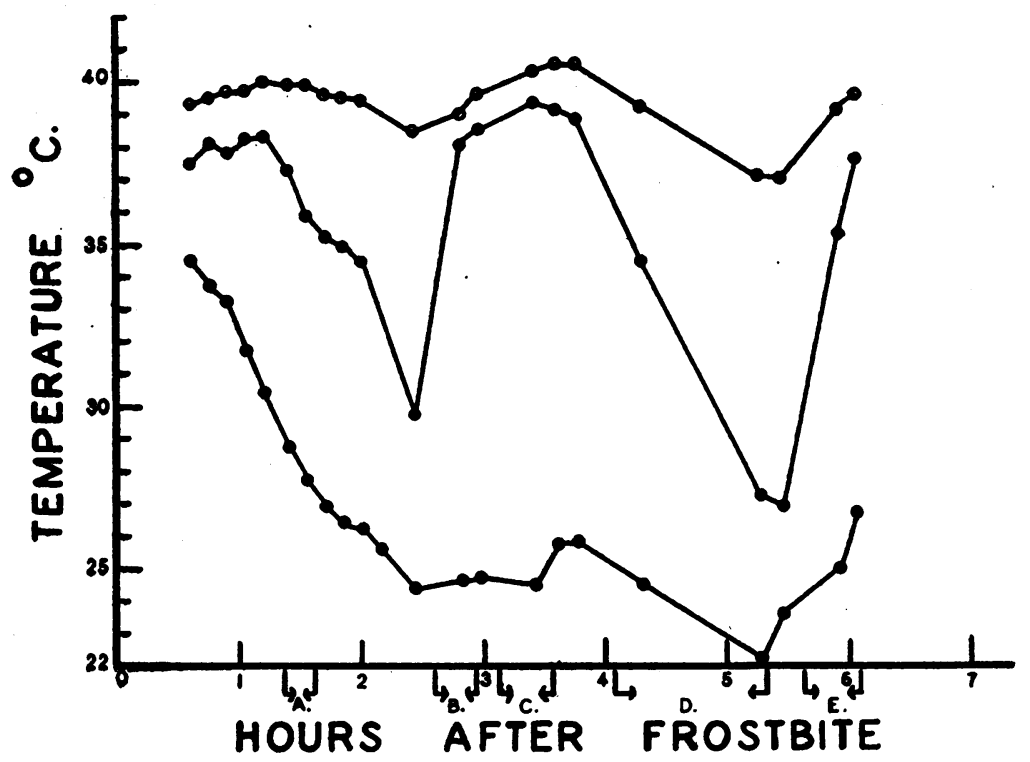

Fig. 4. Skin Temperature Changes in Normal and Frostbitten Rabbit Feet Representing Reflex Responses to General Heating and Cooling

Representative data from one animal. Foot immersed at $-55^{\circ} \mathrm{C}$, for 3 minutes.

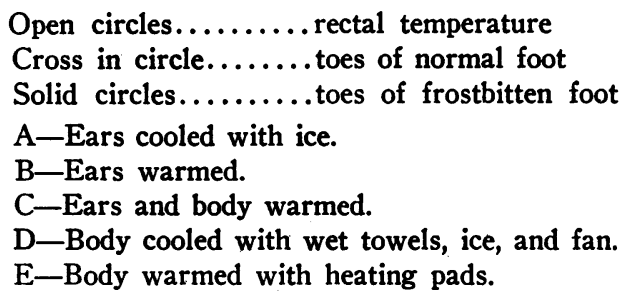

ture were found to be of decided value in predicting the ultimate loss of tissue. The data in the table illustrate the association of low skin temperature of the injured parts and eventual development of gangrene. Following 1-minute exposure at $-55^{\circ} \mathrm{C}$., in the animals in which no tissue loss resulted, the mean temperature differences between the normal and injured feet ranged from $+4.0^{\circ}$ to $-1.9^{\circ} \mathrm{C}$. and the probability that such differences would occur through errors in random sampling ranged from 2 in 100 to 50 in $100(P=0.02$ to 0.5$)$. For comparison with these are 2 animals which lost parts of the toes following exposure for 1 minute at $-55^{\circ} \mathrm{C}$. In both of these animals the temperature of the toes of the injured foot was consistently lower than that of the normal foot. The smaller values of $P$ ( $<0.01$ and 0.001 respectively) indicate that the differences are statistically significant. Fol- lowing 3-minute exposure at $-55^{\circ} \mathrm{C}$., the temperature of the injured feet was always lower than that of the normal feet and these differences are also statistically significant $(P<0.001)$. From the data given in Table $I$ it is apparent that as early as the first 6 hours after injury the temperature of the toes of the injured foot is significantly lower than that of the normal foot in those animals in which the toes are subsequently lost. As described previously this temperature difference becomes more marked with time, so that with the appearance of wet gangrene the temperature of the gangrenous part is only slightly above that of the environment.

\section{Vascular spasm in extremities during the first hours after injury}

Temperature changes in frostbitten and normal extremities of rabbits have been studied during 
the application of heat and cold generally as well as locally to a part remote from that injured by frostbite. In all cases the experiments were carried out during the 7 -hour period immediately following frostbite, at a time when the animals were still anesthetized with dial. The dial was given, in most cases, approximately 1 hour before frostbite.

Similar results have been obtained in a number of animals. A representative experiment is plotted in Figure 4. One hind foot was frostbitten for 3 minutes at $-55^{\circ} \mathrm{C}$. Application of cold to the ears at " $A$ " and to the body at " $D$ " resulted in a temperature drop in the toes of the normal foot of $8.5^{\circ}$ and $12^{\circ} \mathrm{C}$. respectively, while the toes of the frostbitten foot showed much less change in temperature. Application of heat to the ears at " $B$ " and general body warming at " $C$ " and " $E$ " resulted in marked rise in temperature of the normal toes. It is apparent (Figure 4) that after the first $11 / 2$ hours there is a tendency for changes in rectal temperature to be accompanied by changes in skin temperature of the toes of the frostbitten foot.

The temperature changes in the toes of the animal illustrated in Figure 4 and in other animals studied are brought about by changes in blood flow through the tissues. Tittel (5), by direct observation of rabbit ears frozen with solid carbon dioxide, has described a state of passive dilatation of arterioles in the injured region of the ear. This passive dilatation should be regarded as a relative dilatation, and, although constriction may not occur, the size of the vessels may be altered by changes in perfusion pressure. If the arterioles within the injured regions of the feet are in a state of passive dilatation similar to that described by Tittel in rabbit ears following freezing, then blood flow and hence skin temperature should be determined by the perfusion pressure and the patency of the arteries proximal to the level of injury. The rise of skin temperature in uninjured regions following general application of heat demonstrates the existence of adequate systemic arterial pressure. In the injured limb both the failure of signs of vasoconstriction after chilling and of vasodilatation after warming could be explained on the basis of severe spasm of the arteries proximal to the level of injury. Such arterial spasm has been described by Burdenko (6) in human frostbite of the feet where arterial spasm reached as high as the common iliacs. The measurements given in Figure 4 show that the temperatures of the toes of the frostbitten foot were persistently lower than the toes of the normal foot. The course of cooling of the toes in the injured foot shows that there was a progressive reduction of blood flow from 45 minutes after injury to about $21 / 2$ hours after injury. The slope of this line differs little from that describing the fall in temperature of the normal toes when vasoconstriction was induced by the application of cold. It is therefore probable that at the time of measurement, spasm of large arteries on the injured side was occurring and that the spasm was not capable of being relaxed by the usual reflex responses to the application of heat elsewhere on the body.

It should be emphasized that the abnormalities of thermovascular response described above are not interpreted as indications of later vasomotor abnormalities, but are restricted to the first few hours after injury. Studies of skin temperature over a longer period after injury (Figure 3 ) show that the temperature of the toes of rabbit feet injured by cold tend to stabilize at about $28^{\circ} \mathrm{C}$. and that there is usually a slight rise until 48 to 50 hours after injury. The application of cold as illustrated in Figure 4 brought about sufficient reduction of blood flow to bring the toe temperature of the injured foot to approximately $24^{\circ} \mathrm{C}$. while that of the uninjured foot did not fall below $29.5^{\circ} \mathrm{C}$. Thus it is suggested that vasoconstrictor responses to cold may be potentiated locally by recent cold injury but that central inhibition of vasoconstrictor discharges over the vasomotor neurons supplying the vessels of the injured extremity is not evoked by the local or general application of heat.

\section{SUM MARY}

Rabbits' feet and ears, frostbitten by immersion in liquid at temperatures from $-15^{\circ}$ to $-70^{\circ} \mathrm{C}$. for varying lengths of time, undergo a series of changes which, for a given time and temperature, are constant and reproducible. Upon removal from the cold liquid the part is solidly frozen, but is not brittle. Massive edema develops with the 
reestablishment of blood flow to the part. After 3 to 4 days, in those instances in which the injury is of sufficient severity, wet gangrene develops. Drying begins 4 to 6 days after injury, resulting in mummification of the foot or ear which eventually separates near the line to which it was immersed in the freezing mixture.

Observations of the skin color of the injured region and measurements of skin temperature indicate that for a time after injury blood flows through the injured region, often at a faster rate than in the normal foot or ear. During the first 50 hours after injury there is a progressive fall in skin temperature of frostbitten ears, until a level approximately equal to room temperature is reached coincidentally with the occurrence of wet gangrene. Comparison of skin temperature of the toes of frostbitten feet with the temperature of the normal foot indicates that in those animals in which the injury is of sufficient severity to result in subsequent loss of the toes, there is a significant decrease in temperature of the injured foot below that of the normal foot during the first 6 hours after injury. This difference becomes more marked with time.

\section{BIBLIOGRAPHY}

1. Fuhrman, F. A., and Crismon, J. M., Studies on gangrene following cold injury. I. A method for producing gangrene by means of controlled injury by cold. J. Clin. Invest., 1947, 26, 229.

2. Ariev, T. Y., Experimental observations on the brittleness of frozen extremities. Vestn. Khirur., 1937, 52, 63.

63.

3. Fuhrman, F. A., and Crismon, J. M., Studies on gangrene following cold injury. III. Edema following cold injury: its magnitude and the composition and source of edema fluid. J. Clin. Invest., 1947, 26, 245.

4. Fisher, R. A., Statistical Methods for Research Workers. Ed. 6, London, Oliver and Boyd, 1936, p. 130.

5. Tittel, S., Ueber die Reaktionsweise des Gefässsystems bei lokaler Erfrierung. I. Die Art des Reaktionsablaufes an den einzelnen Abschnitten des Gefässsystems. Ztschr. ges. exper. Med., 1943, 113, 698.

6. Burdenko, N. N., The effect of frostbite on the sympathetic nervous system. Amer. Rev. Sov. Med., 1943, 1, 15. From Khirurgia, 1942, No. 5-6, 3. 